\title{
Pelvic nodal radiotherapy in Gleason grade group 5 prostate cancer
}

\author{
Kiri Cook ${ }^{1}$, Amar U. Kishan ${ }^{2}$ \\ ${ }^{1}$ Department of Radiation Medicine, Oregon Health and Science University, Portland, OR 97239, USA; ${ }^{2}$ Deparmtnet of Radiation Oncology, \\ University of California, Suite B265, Los Angeles, CA 90095, USA \\ Correspondence to: Amar U. Kishan, MD. 200 UCLA Medical Plaza, University of California, Suite B265, Los Angeles, CA 90095, USA. \\ Email: aukishan@mednet.ucla.edu. \\ Response to: Taussky D, Delouya G. Is pelvic prophylactic radiotherapy in prostate cancer just right? Transl Androl Urol 2020;9:2296-8.
}

Submitted May 08, 2020. Accepted for publication Jun 19, 2020.

doi: $10.21037 /$ tau-20-917

View this article at: http://dx.doi.org/10.21037/tau-20-917

We read the Editorial Comment by Taussky and Delouya with great interest (1). They pose the question: why do radiation oncologists continue to debate whole pelvis radiation therapy (WPRT) given that two negative randomized trials have been published? We would counter that this discussion can and should continue for a number of reasons, the foremost being that the jury is still out.

One must first acknowledge that the purported benefit of WPRT can only be realized if there is microscopic disease in the pelvic lymph nodes. If patients have too low of a risk of nodal disease (as would be expected of the patients on Groupe d'etudes des tumeurs urogenitales (GETUG)-1, and most patients with Gleason grade group 1-2 disease), then WPRT would offer no benefit above prostateonly radiotherapy. If patients have too high of a risk of extrapelvic disease, then WPRT would also offer no benefit over prostate-only radiotherapy. Thus, as Chen alluded to in his initial Editorial about our manuscript, one must find a clinical situation in which the risk of having microscopic disease is "just right" to warrant a benefit to WPRTthe "Goldilocks problem" (2). Taussky and Delouya argue that our previous article does not "put WPRT in the 'just right' category." We assume that by their statement, the authors mean that we have not identified this group either. On the contrary, our intent was not to say which porridge is the right temperature, only to say whether it was too hot or too cold for patients with Gleason grade group 5 prostate cancer. This is a question that has certainly not been answered by any previous randomized trial. In fact, RTOG 9413-a four arm trial—enrolled a grand total of
139 patients with Gleason grade group 5 disease, while the GETUG-01 trial enrolled 99 patients with Gleason grade group 4-5 disease (of which the majority likely had Gleason grade group 4 disease). This leaves a maximum of 238 patients across six trial arms from two trials, none of which included stratification for Gleason grade group 5 disease and none of which reported outcomes in this subgroup. Is the role of WPRT really settled in this subgroup?

It is also important to acknowledge the design and limitations of these trials. RTOG 9413, with its complex, factorial design was initiated to examine both the sequencing of androgen deprivation therapy (ADT) and the role of WPRT. The updated 10-year results do show evidence of a benefit in progression free-survival and biochemical failure when comparing WPRT to prostateonly radiotherapy among men receiving neoadjuvant and concurrent hormonal therapy. The major criticism is that outcomes in men receiving prostate-only radiotherapy with adjuvant ADT were similarly good. This a priori unexpected interaction of the sequencing of ADT with radiation field size complicated the results, though one could argue that if men are to receive neoadjuvant/concurrent ADT, the trial supports WPRT. The GETUG-1 study, which did not show a difference in progression-free survival, admittedly had a more straightforward design (3). The differences in patient populations, treatment fields, and use of ADT have been discussed extensively (4-6) and cannot be repeated here due to space constraints. But a critical consideration for both trials is the low dose of radiation given to the primary tumor. With emerging evidence that local control 
can translate to improved clinical outcomes (7-9), we must consider whether local control needs to be optimized before a benefit to WPRT can be seen.

We, like the authors of the Editorial Comment, eagerly await the results of RTOG 0924 (which will likely meaningfully report in approximately 10 years, not in 2021 as the authors state) as well as the PIVOTAL trial [NCT01685190]. But we acknowledge that well-designed randomized trials are incredibly resource intensive, requiring not only significant expenditure of time and money, but also the sacrifices of patients who are willing to be randomized on a trial. A decade's worth of patients will need our help making decisions about their treatment before then. And even when these trials report, as was the case with RTOG 9413 and GETUG-01, who is to say that patients with Gleason grade group 5 disease will be wellrepresented in the patient populations?

Moreover, as the authors of the Editorial Comment themselves point out, data from advanced imaging studies do in fact confirm that a fair number of appropriately selected patients indeed have microscopic disease in the pelvis. Should such patients not be considered for WPRT because RTOG 9413 and GETUG-01 were negative? While that argument could be made, it would appear the authors themselves advocate in using PSMA PET/CT to guide treatment. But what should be done if a PSMA PET were not available, or if we were to acknowledge that the sensitivity is not $100 \%$ ? Would this not imply a role for WPRT in selected patients?

In medicine, one must be careful not to throw out the baby with the bathwater. The vast heterogeneity amongst patient and disease characteristics within oncology frustratingly makes us unable to make confident clinical decisions based on sweeping generalizations. Our goal is continuing to granulize the indications for treatments. In the meantime, we must discuss and debate complex questions, involve patients in the decision-making process, and conduct research that will further the field to the best of our ability.

\section{Acknowledgments}

Funding: None.

\section{Footnote}

Provenance and Peer review: This article was commissioned by the editorial office, Translational Andrology and Urology.
The article did not undergo external peer review.

Conflicts of Interest: Both authors have completed the ICMJE uniform disclosure form (available at http:// dx.doi.org/10.21037/tau-20-917). AUK reports grants and personal fees from ViewRay, Inc., personal fees from Varian Medical Systems, Inc., from Intelligent Automation, Inc., other from Janssen, Inc., outside the submitted work. The other author has no conflicts of interest to declare.

Ethical Statement: The authors are accountable for all aspects of the work in ensuring that questions related to the accuracy or integrity of any part of the work are appropriately investigated and resolved.

Open Access Statement: This is an Open Access article distributed in accordance with the Creative Commons Attribution-NonCommercial-NoDerivs 4.0 International License (CC BY-NC-ND 4.0), which permits the noncommercial replication and distribution of the article with the strict proviso that no changes or edits are made and the original work is properly cited (including links to both the formal publication through the relevant DOI and the license). See: https://creativecommons.org/licenses/by-nc-nd/4.0/.

\section{References}

1. Taussky D, Delouya G. Is pelvic prophylactic radiotherapy in prostate cancer just right? Transl Androl Urol 2020;9:2296-8.

2. Chen RC. Randomized Trials and the Goldilocks Problem. Eur Urol 2020;77:11-3.

3. Pommier P, Chabaud S, Lagrange JL, et al. Is There a Role for Pelvic Irradiation in Localized Prostate Adenocarcinoma? Update of the Long-Term Survival Results of the GETUG-01 Randomized Study. Int J Radiat Oncol Biol Phys 2016;96:759-69.

4. Lawton CA, DeSilvio M, Roach M 3rd, et al. An update of the phase III trial comparing whole pelvic to prostate only radiotherapy and neoadjuvant to adjuvant total androgen suppression: updated analysis of RTOG 94-13, with emphasis on unexpected hormone/radiation interactions. Int J Radiat Oncol Biol Phys 2007;69:646-55.

5. Koontz BF, Dal Pra A. Shifting the Curtain-Can We Make Sense of the Whole Pelvis Controversy? Int J Radiat Oncol Biol Phys 2020;106:534-6.

6. Crook J. Prostate cancer: Elective pelvic nodal radiotherapy: is the jury still out? Nat Rev Urol 
2016;13:10-1.

7. Michalski JM, Moughan J, Purdy J, et al. Effect of Standard vs Dose-Escalated Radiation Therapy for Patients With Intermediate-Risk Prostate Cancer: The NRG Oncology RTOG 0126 Randomized Clinical Trial. JAMA Oncol 2018;4:e180039.

8. Kishan AU, Cook RR, Ciezki JP, et al. Radical Prostatectomy, External Beam Radiotherapy, or

Cite this article as: Cook K, Kishan AU. Pelvic nodal radiotherapy in Gleason grade group 5 prostate cancer. Transl Androl Urol 2020;9(5):2326-2328. doi:10.21037/tau-20-917
External Beam Radiotherapy With Brachytherapy Boost and Disease Progression and Mortality in Patients With Gleason Score 9-10 Prostate Cancer. JAMA 2018;319:896-905.

9. Kishan AU, Chu FI, King CR, et al. Local Failure and Survival After Definitive Radiotherapy for Aggressive Prostate Cancer: An Individual Patient-level Meta-analysis of Six Randomized Trials. Eur Urol 2020;77:201-8. 